Revista Thema

V.17

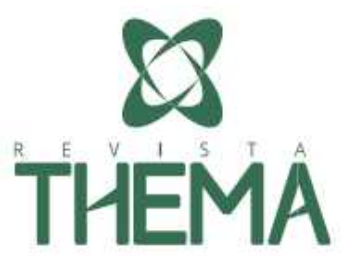

CIÊNCIAS AGRÁRIAS

\title{
Avaliação de sistemas de produção convencional, racionais integrados e orgânicos na cultura da cebola em cultivo convencional e de plantio direto
}

\section{Evaluation of conventional, integrated rational and organic production systems in onion culture in conventional and no- till cultivation}

Francisco Olmar Gervini Menezes Júnior ${ }^{1}$,

Paulo Antônio de Souza Gonçalves², Leandro Luiz Marcuzzo ${ }^{3}$

\section{RESUMO}

O desenvolvimento de sistemas de produção sustentáveis é de fundamental importância para disponibilizar à população alimentos seguros ao consumo. O estudo foi realizado no município de Ituporanga-SC (27038'S, 4960'O, altitude de $475 \mathrm{~m}$ ), em 2014 e 2015. O objetivo foi avaliar a produtividade (comercial total, classe 2 , classe 3 , e classe acima de 3 ), incidência de tripes, severidade de míldio, florescimento e armazenamento (perda pós-colheita), em sistemas de produção convencional, racionais integrados e orgânicos estabelecidos em cultivo convencional e de plantio direto. O cultivo em plantio direto aumenta a produtividade comercial total e da classe 3 em relação ao plantio convencional. A produtividade de bulbos da classe acima de 3 é maior em plantio direto. A produtividade comercial total e de bulbos da classe acima de 3 são superiores em tratamento convencional. A produtividade da classe 3 é similar entre tratamentos convencional e racional II em plantio direto. Maior formação de bulbos classe 2 é observada nos tratamentos orgânicos. A severidade de míldio foi superior em tratamentos orgânicos $>$ racionais $>$ convencional. O manejo fitossanitário utilizado no tratamento convencional é mais eficiente na redução da severidade de míldio em relação ao realizado nos racionais e orgânicos, e o empregado nos tratamentos racionais é mais eficiente em relação ao utilizado nos orgânicos. A incidência de tripes é menor em sistema de plantio direto. O florescimento é maior em plantio direto. Maiores perdas em pós-colheita ocorrem em plantio convencional.

Palavras-chave: Allium cepa; produção integrada; fitossanidade; florescimento; pós-colheita.

\section{ABSTRACT}

The development of sustainable production systems is crucial to provide the population safe food for consumption. The study was carried out in the municipality of Ituporanga-SC (27038'S,

\footnotetext{
${ }^{1}$ Empresa de Pesquisa Agropecuária e Extensão Rural de Santa Catarina - Epagri, Florianópolis/SC Brasil. E-mail: franciscomenezes@epagri.sc.gov.br

${ }^{2}$ Idem. E-mail: pasg@epagri.sc.gov.br

${ }^{3}$ Instituto Federal de Educação, Ciência e Tecnologia Catarinense - IFC, Campus Rio do Sul/SC - Brasil. Email: leandro.marcuzzo@ifc.edu.br
} 
$499^{\circ} 60^{\prime} \mathrm{O}$, altitude of $475 \mathrm{~m}$ ), in 2014 and 2015. The objective was to evaluate the productivity (total commercial, class 2, class 3 and class above 3), trips incidence, downy mildew severity, flowering and storage (post-harvest loss) in conventional, integrated rational and organic systems established in conventional and no-tillage cultivation. No-till cultivation increases total commercial productivity and class 3 in relation to conventional planting. The productivity of bulbs of class above 3 is higher in no-tillage. Total commercial productivity and bulbs of class above 3 are superior in conventional treatment. The productivity of class 3 is similar between conventional and rational treatments II in no-tillage. Higher class 2 bulb formation is observed in organic treatments. The severity of mildew was higher in conventional> rational> organic treatments. The phytosanitary management used in the conventional treatment is more efficient in reducing the severity of mildew than in the rational and organic ones, and the employee in the rational treatments is more efficient than the one used in the organic ones. The incidence of thrips is lower in no-tillage system. Flowering is greater in no-tillage. Higher post-harvest losses occur in conventional planting.

Keywords: Allium cepa; integrated production; phytosanity; flowering; post-harvest.

\section{INTRODUÇÃO}

O estado de Santa Catarina (SC), notabiliza-se por ser o maior produtor nacional de cebola. Atividade tipicamente conduzida por agricultores familiares, responsável por significativa geração de renda, emprego e fixação do homem ao meio rural. Estimativas recentes indicam que somente em SC a cultura envolva 8.289 estabelecimentos (IBGE, 2018). Na safra de 2017/18, a produção comercializada no estado foi de $377.357,37$ t, colhidas em 19.596 ha com rendimento médio de $19.26 \mathrm{t}$ ha-1, responsável por gerar uma renda bruta de $\mathrm{R} \$ 377,36$ milhões.

Contudo, percebe-se que em considerável parte das áreas cultivadas têm sido adotados sistemas de produção insustentáveis em que são comuns a intensa mobilização do solo, excesso de fertilizantes e agrotóxicos, práticas que favorecem desequilíbrios nutricionais e elevam os custos de produção e os riscos de contaminação do produtor, do ambiente e do consumidor. Diversas práticas que deveriam ser consideradas rotineiras, como análise de solo e plantio direto, são pouco utilizadas. Áreas com excesso de fósforo e potássio são anualmente readubadas desconsiderando a análise do solo, sendo comum o uso de calendários de aplicação de produtos fitossanitários sem qualquer parâmetro técnico racional. (MENEZES JÚNIOR et al., 2018).

Notadamente, tal manejo fitossanitário tem sido realizado para a principal doença e praga na fase de lavoura de cebola ocorrentes na região Sul do Brasil, o míldio, Peronospora destructor (Berk.) Casp. Ex Berk. (Peronosporales: Peronospora Corda) e o tripes, Thrips tabaci Lind. (Thysanoptera: Thripidae), respectivamente. (GONÇALVES, 2016; MARCUZZO; ARAÚJO, 2016). Estes se constituem nos principais alvos de manejo fitossanitário no estado de Santa Catarina, onde tem-se registrado o uso frequente e, por vezes, inadequado do controle químico.

A mudança dessa realidade com a incorporação de técnicas que racionalizem o uso de insumos, aumentem a produtividade, são fundamentais para a produção de alimentos seguros ao consumo, para o aumento dos rendimentos financeiros e manutenção dos agricultores na atividade. Para tal, há necessidade de incorporação das chamadas 
Boas Práticas Agrícolas. Essas, de acordo com Menezes Júnior (2016), constituem-se na base dos Sistemas de Produção Integrada demandados pelo Ministério da Agricultura, Pecuária e Abastecimento.

O objetivo desse estudo foi avaliar sistemas de produção convencional, integrados e orgânicos, em preparo do solo convencional e de plantio direto, por meio da produtividade, incidência de tripes, severidade de míldio, florescimento e armazenamento em pós-colheita, nas condições do Alto Vale do Itajaí-SC, para o cultivar de cebola Empasc 352 Bola Precoce.

\section{MATERIAL E MÉTODOS}

O estudo constou de dois experimentos conduzidos em 2014 e 2015 na Epagri/ Estação Experimental de Ituporanga, localizada em Ituporanga-SC (27ㅇ3's, 4960'O, altitude de $475 \mathrm{~m}$ ). Segundo a classificação de Köeppen, o clima local é do tipo Cfa. A cultivar utilizada, devido ocupar mais de $60 \%$ da área de cebola cultivada no estado de Santa Catarina, foi a Empasc 352 Bola Precoce. O solo da área experimental é classificado como Cambissolo Háplico de textura argilosa.

As mudas foram produzidas com base nos referenciais tecnológicos propostos pelo Sistema de Produção para a Cebola (Epagri, 2013). As semeaduras foram realizadas em 24/04/2014 e 23/04/2015 e os transplantes em 04/07/2014 e 08/07/2015, respectivamente para os experimentos 1 e 2 (Exp 1 e 2). As colheitas dos bulbos foram realizadas quando as plantas apresentavam mais de $70 \%$ de tombamento natural, em 31/10/2014 (solo com plantas de cobertura em sistema de plantio direto) e 11/11/2014 (solo nú em plantio convencional) para o Exp1 e em 17/11/15 (plantio direto e convencional) para o $\operatorname{Exp} 2$.

As análises de solo das áreas experimentais foram realizadas antes da instalação dos ensaios, com profundidade de amostragem de 0-20 cm (Tabela 1).

Os experimentos foram estabelecidos, em cada ano agrícola, em áreas adjacentes com preparo do solo convencional - PC ("solo nú" com aração e gradagem) e em área com plantio direto consolidado - PD. Na área PC foram semeados, em dezembro do ano anterior a instalação dos experimentos, o milheto. A área PD foi semeada no início de janeiro de 2013 e final de dezembro de 2014 com plantas de cobertura/adubação verde a mucuna e o milheto, nas densidades de 40 e $30 \mathrm{~kg}$ de sementes $\mathrm{ha}^{-1}$, respectivamente. Nas áreas de PC o milheto foi dessecado e incorporado ao solo antes do transplante das mudas. Nas áreas PD, que receberam mucuna e milheto, as plantas de cobertura/adubação verde foram manejadas esperando que sua secagem natural ou com herbicida (glifosato), acamadas com rolo faca ou grade de discos e deixadas sobre o solo antes do transplante.

Os tratamentos consistiram de sete sistemas de produção aplicados em sistema de preparo convencional (PC) e de plantio direto (PD), descritos a seguir.

Convencional, adubação com $125 \mathrm{~kg}$ de $\mathrm{N} \mathrm{ha}^{-1}$, aplicados da dose total, 25\%, 50\% e $25 \%$ respectivamente no plantio, 45 e 65 dias após; $160 \mathrm{~kg}$ de $\mathrm{P}_{2} \mathrm{O}_{5} \mathrm{ha}^{-1}$ e $90 \mathrm{~kg}$ de $\mathrm{K}_{2} \mathrm{O}$ ha $^{-1}$ aplicados no plantio; pulverização semanal alternada até o final do ciclo dos fungicidas metalaxil-m mancozebe e metalaxil-m clorotalonil; e a partir do final de 


\section{Revista Thema}

setembro ao fim do ciclo de forma alternada dos inseticidas lambda-cialotrina e imidacloprido.

Tabela 1 - Dados de análise do solo das áreas cultivadas em sistema de plantio convencional (PC) e plantio direto (PD) em 2014 (Exp 1) e 2015 (Exp 2).

Epagri, Ituporanga, SC.

\begin{tabular}{|c|c|c|c|c|c|c|c|}
\hline & \multicolumn{7}{|c|}{2014 (Exp 1) } \\
\hline & $\begin{array}{l}\text { Argila } \\
\mathrm{g} \mathrm{dm}^{-3}\end{array}$ & $\begin{array}{l}\mathrm{pH} \\
\left(\mathrm{H}_{2} \mathrm{O}\right)\end{array}$ & $\begin{array}{l}\mathrm{pH} \\
\text { (SMP) }\end{array}$ & $\begin{array}{l}\text { M.O. } \\
\text { g dm³ }\end{array}$ & $\begin{array}{l}\mathrm{P} \text { (Mehlich-1) } \\
\mathrm{g} \mathrm{\textrm {dm } ^ { - 3 }}\end{array}$ & $\begin{array}{l}\mathrm{K} \\
\mathrm{mmolc} \\
\mathrm{dm}^{-3}\end{array}$ & $\begin{array}{l}\mathrm{H}+\mathrm{Al} \\
\mathrm{mmolc} \mathrm{dm}^{-3}\end{array}$ \\
\hline PC & 500 & 6,2 & 6,4 & 29,0 & 17,0 & 4,5 & 27,0 \\
\hline \multirow[t]{2}{*}{ PD } & 517 & 5,8 & 6,0 & 27,0 & 72,8 & 4,2 & 43,0 \\
\hline & \multicolumn{2}{|l|}{$\begin{array}{l}\text { CTC (pH 7,0) } \\
\text { mmolc } \mathrm{dm}^{-3}\end{array}$} & \multicolumn{2}{|c|}{$\begin{array}{l}\text { Al } \\
\text { mmolc } \mathrm{dm}^{-3}\end{array}$} & \multicolumn{2}{|l|}{$\begin{array}{l}\mathrm{Ca} \\
\mathrm{mmolc} \mathrm{dm}^{-3}\end{array}$} & $\begin{array}{l}\mathrm{Mg} \\
\mathrm{mmolc} \mathrm{dm}^{-3}\end{array}$ \\
\hline \multirow[t]{3}{*}{ PD } & $\begin{array}{l}153,0 \\
205,0\end{array}$ & & $\begin{array}{l}0,0 \\
0,0\end{array}$ & & $\begin{array}{l}83,0 \\
105,0\end{array}$ & & $\begin{array}{l}39,0 \\
53,0\end{array}$ \\
\hline & \multicolumn{7}{|c|}{$2015(\operatorname{Exp} 2)$} \\
\hline & $\begin{array}{l}\text { Argila } \\
\mathrm{g} \mathrm{dm}^{-3}\end{array}$ & $\begin{array}{l}\mathrm{pH} \\
\left(\mathrm{H}_{2} \mathrm{O}\right)\end{array}$ & $\begin{array}{l}\mathrm{pH} \\
\text { (SMP) }\end{array}$ & $\begin{array}{l}\text { M.O. } \\
\text { g dm³ }\end{array}$ & $\begin{array}{l}\mathrm{P} \text { (Mehlich-1) } \\
\mathrm{g} \mathrm{dm^{-3 }}\end{array}$ & $\begin{array}{l}\mathrm{K} \\
\mathrm{mmolc} \\
\mathrm{dm}^{-3}\end{array}$ & $\begin{array}{l}\mathrm{H}+\mathrm{Al} \\
\mathrm{mmolc} \mathrm{dm}^{-3}\end{array}$ \\
\hline PC & 510 & 6,0 & 6,3 & 31,0 & 23,3 & 5,2 & 32,0 \\
\hline \multirow[t]{2}{*}{ PD } & 440 & 5,5 & 5,7 & 31,0 & 44,5 & 4,7 & 62,0 \\
\hline & \multicolumn{2}{|l|}{$\begin{array}{l}\text { CTC (pH 7,0) } \\
\text { mmolc dm-3 }\end{array}$} & \multicolumn{2}{|c|}{$\mathrm{mmolc} \mathrm{dm}^{-3}$} & \multicolumn{2}{|l|}{$\begin{array}{l}\mathrm{Ca} \\
\mathrm{mmolc} \mathrm{dm}^{-3}\end{array}$} & $\begin{array}{l}\mathrm{Mg} \\
\mathrm{mmolc} \mathrm{dm}^{-3}\end{array}$ \\
\hline $\begin{array}{l}\text { PC } \\
\text { PD }\end{array}$ & \multicolumn{2}{|l|}{157,6} & \multicolumn{2}{|l|}{0,0} & \multicolumn{2}{|l|}{82,0} & $\begin{array}{l}39,0 \\
42,0\end{array}$ \\
\hline
\end{tabular}

Fonte: Autores.

Racional I, adubação recomendada pela CQFS-RS/SC (2004), $75 \mathrm{~kg}$ de N ha-1 , aplicado $50 \%$ da dose total no plantio, e o restante 45 dias após; $120 \mathrm{~kg}$ de $\mathrm{P}_{2} \mathrm{O}_{5} \mathrm{ha}^{-1}$ e $90 \mathrm{~kg}$ de $\mathrm{K}_{2} \mathrm{O} \mathrm{ha}^{-1}$ aplicados no plantio; pulverização, um mês após transplante, alternada até o final do ciclo dos fungicidas metalaxil-m mancozebe e oxicloreto de cobre; e duas aplicações alternadas dos inseticidas lambda-cialotrina e imidacloprido, uma no final de setembro e outra uma semana após no início de outubro de 2013.

Racional II, adubação com $125 \mathrm{~kg}$ de $\mathrm{N} \mathrm{ha}^{-1}$, aplicados da dose total, 25\%, 50\% e $25 \%$, respectivamente no plantio, 45 e 65 dias após; $120 \mathrm{~kg}$ de $\mathrm{P}_{2} \mathrm{O}_{5} \mathrm{ha}^{-1}$ e $90 \mathrm{~kg}$ de $\mathrm{K}_{2} \mathrm{O}$ ha $^{-1}$ aplicados no plantio; mesmo tratamento fitossanitário de racional I. Nos tratamentos convencional, racional I e racional II utilizaram-se respectivamente como fontes de $\mathrm{N}, \mathrm{P}_{2} \mathrm{O}_{5}$ e $\mathrm{K}_{2} \mathrm{O}$ o nitrato de amônio, o superfosfato triplo e o cloreto de potássio.

Orgânico I, adubação com $75 \mathrm{~kg} \mathrm{~N}^{-1}$, aplicados $20 \%$ no plantio e o restante 45 dias após; $160 \mathrm{~kg}$ de $\mathrm{P}_{2} \mathrm{O}_{5} \mathrm{ha}^{-1}$, tendo como fontes respectivamente esterco de aves e fosfato natural; tratamento fitossanitário iniciado 30 dias após o transplante com oxicloreto de cobre pulverizado quinzenalmente no total de cinco aplicações. 
Orgânico II, adubação com $125 \mathrm{~kg} \mathrm{~N} \mathrm{ha}^{-1}$, aplicados respectivamente 25\%, 50\% e $25 \%$ da dose total no plantio, 45 e 65 dias após; $160 \mathrm{~kg}$ de $\mathrm{P}_{2} \mathrm{O}_{5}$ ha-1 , tendo como fontes esterco de aves e fosfato natural, respectivamente; e mesmo tratamento fitossanitário de orgânico I.

Orgânico III, tratamento orgânico I com aplicação foliar de preparado homeopático de calcário de conchas $6 \mathrm{CH} 0,5 \%$.

Orgânico IV, tratamento orgânico II com aplicação foliar de preparado homeopático

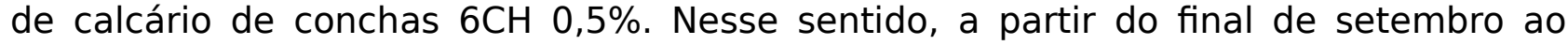
período de colheita foi pulverizado semanalmente calcário de conchas $6 \mathrm{CH}$, totalizando 6 aplicações. As doses aplicadas de fungicidas e inseticidas seguiram as recomendadas pelos fabricantes.

O delineamento experimental utilizado foi o de blocos ao acaso, com quatro repetições. A área total de cada parcela experimental foi de 9,6 $\mathrm{m}^{2}$ (área útil 6,9 $\mathrm{m}^{2}$ ). Nessa o transplante das mudas foi realizado de forma a se obter uma densidade populacional equivalente a 400 mil plantas ha-1. O espaçamento utilizado foi o de 33 $\mathrm{cm}$ entre linhas e $7,5 \mathrm{~cm}$ entre plantas.

A produtividade comercial total (PCT) foi considerada com os bulbos com diâmetro transversal - (DT) acima de $35 \mathrm{~mm}$; produtividade classe 2 (Cx2, DT de 35 a $50 \mathrm{~mm}$ ); produtividade classe $3(\mathrm{C} \times 3, \mathrm{DT}>50 \mathrm{~mm}$ a $70 \mathrm{~mm})$; produtividade classe $3+(\mathrm{C} \times 3+$, DT $>50 \mathrm{~mm}$ ).

A severidade final de míldio, Peronospora destructor (SM\%) foi estimada visualmente pela análise da área foliar afetada pela doença (0 a 100\%) em cada folha conforme Wordell Filho e Stadnik (2006).

A incidência de tripes, Thrips tabaci foi avaliada em cinco plantas ao acaso por parcela em todas as folhas com escala visual de notas. As notas foram atribuídas, respectivamente, com valores de 1, 3 e 9, para níveis de incidência baixo, médio e alto, segundo Gonçalves et al. (2014).

A percentagem de florescimento (Floresc\%) foi avaliada no final do ciclo. A percentagem de perda em pós-colheita (PPC\%) foi determinada após 4 meses de armazenamento, sendo considerada a perda da massa fresca inicial dos bulbos.

O crescimento e desenvolvimento das plantas foi correlacionado com as condições meteorológicas. O ciclo de crescimento e desenvolvimento da cebola pode ser dividido em desenvolvimento inicial (estabelecimento inicial), desenvolvimento foliar, início da bulbificação, período entumescimento (ou "enchimento") e maturação dos bulbos. Na análise de correlação do desenvolvimento de plantas com variáveis meteorológicas foram divididos esses períodos em desenvolvimento foliar (período do estabelecimento inicial ao final do desenvolvimento foliar) e de desenvolvimento dos bulbos (início da bulbificação a maturação dos bulbos). Na Tabela 2 e Figura 1 são descritas as condições meteorológicas ocorrentes nos anos de 2014 e 2015 para os períodos de desenvolvimento da cebola.

Os dados experimentais, conforme sua natureza, foram submetidos à análise de variância, correlação e teste de Tukey a 5\% de probabilidade de erro com o programa estatístico "R". 


\section{Revista Thema}

Tabela 2 - Variáveis meteorológicas ocorrentes nos períodos de desenvolvimento da cebola nos anos agrícolas de 2014 e 2015. Epagri, Ituporanga, SC.

\begin{tabular}{lcccccc}
\hline $\begin{array}{l}\text { Variáveis } \\
\text { meteorológicas }\end{array}$ & $\begin{array}{c}\text { Desenvolvimento } \\
\text { inicial }\end{array}$ & $\begin{array}{c}\text { Desenvolvimento e } \\
\text { maturação dos bulbos }\end{array}$ & \multicolumn{2}{c}{ Médias } \\
\hline & Julho a setembro & Outubro a novembro & \multicolumn{2}{c}{ Ciclo } \\
\hline & $\mathbf{2 0 1 4}$ & $\mathbf{2 0 1 5}$ & $\mathbf{2 0 1 4}$ & $\mathbf{2 0 1 5}$ & $\mathbf{2 0 1 4}$ & $\mathbf{2 0 1 5}$ \\
\hline To média & 16,33 & 16,00 & 21,00 & 19,00 & 18,67 & 17,50 \\
To min média & 11,67 & 12,67 & 16,50 & 16,00 & 14,09 & 14,34 \\
To máx média & 21,33 & 23,00 & 25,50 & 23,50 & 23,42 & 23,25 \\
To min abs* media & 4,00 & 6,33 & 10,00 & 12,50 & 7,00 & 9,42 \\
To máx abs* media & 28,33 & 30,00 & 32,00 & 33,00 & 30,17 & 31,50 \\
Precipitação (mm) & 395,50 & 346,40 & 237,10 & 466,80 & 632,6 & 813,2 \\
UR\% & 85,00 & 81,13 & 78,50 & 83,50 & 81,8 & 82,3 \\
\hline
\end{tabular}

*abs = absoluta.

Fonte: Autores.

Figura 1 - Distribuição de precipitação $(\mathrm{mm})$ durante o período experimental para os anos de 2014 e 2015. Epagri, Ituporanga, SC.

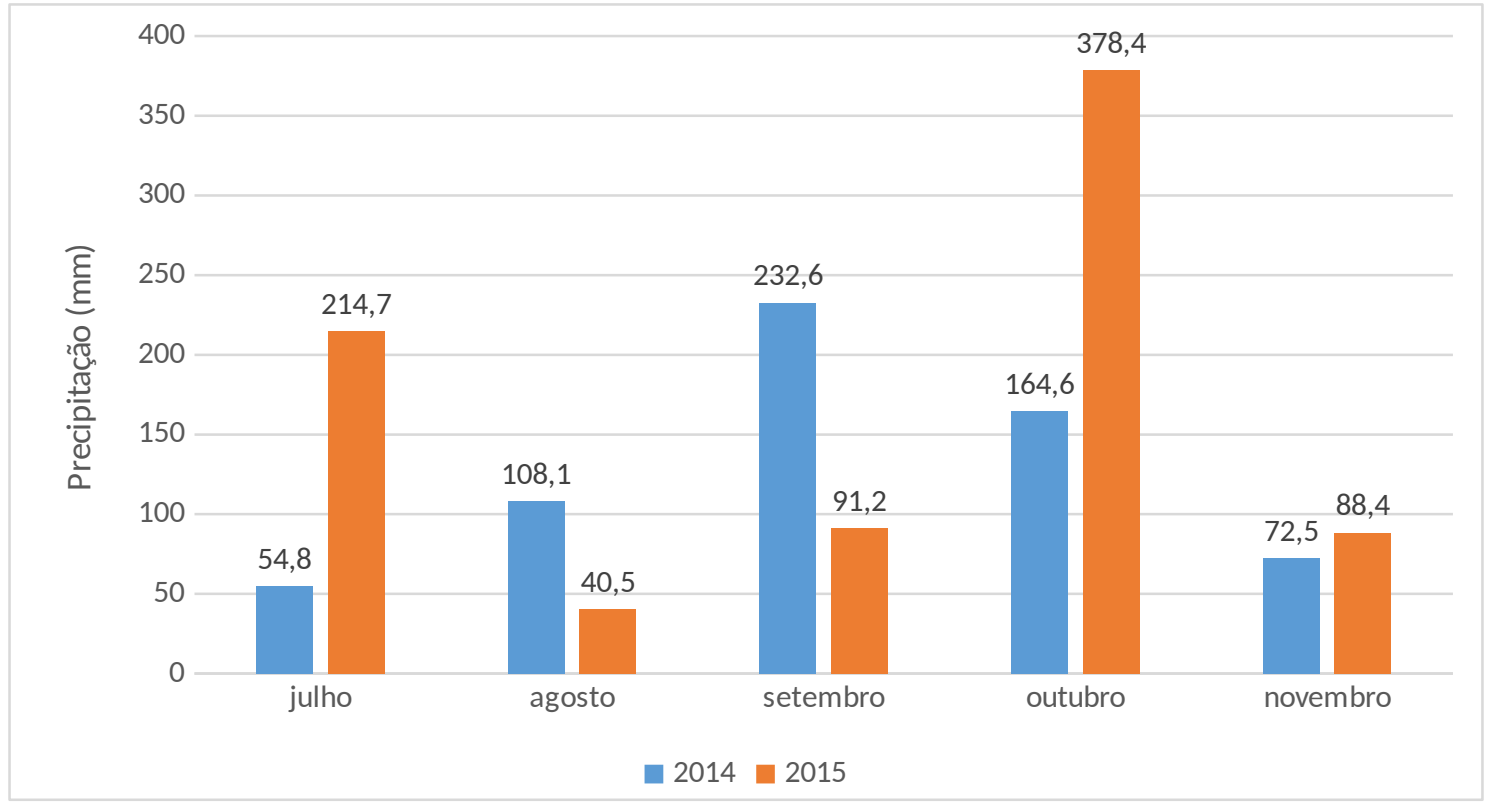

Fonte: Autores.

\section{RESULTADOS E DISCUSSÃO}

\subsection{PRODUTIVIDADE COMERCIAL TOTAL (PCT)}

Para a PCT, em ambos os anos agrícolas, não houve interação entre os fatores $(p>0,05)$ sistema de preparo do solo, plantio convencional (PC) e plantio direto (PD) e os tratamentos aplicados. Em relação ao preparo do solo verificam-se maiores PCTs para o sistema de plantio direto, em média $9 \%$ superiores ao sistema de preparo do solo PC (Tabela 3). Isso, possivelmente, ocorreu em função dos efeitos benéficos oriundos do uso de plantas de cobertura de verão e dos resíduos deixados sobre o solo no plantio da cebola. O sistema de PD proporciona maior umidade e armazenamento de água pelo solo, reduz a temperatura solo, aumenta a atividade microbiana do solo, melhora da estrutura do solo, a infiltração de água, a probabilidade de drenagem 
quando há chuvas mais intensas e abundantes, aumenta a disponibilidade de nutrientes, reduz a lixiviação do nitrato e aumenta a eficiência dos fertilizantes aplicados. (SCOPEL et al., 2005; BAYER et al., 2009; ALTMAN, 2010).

Tabela 3 - Produção comercial total (PCT), produtividade de bulbos de classe superior a $3(\mathrm{C} \times 3+)$ e perda pós-colheita (PPC). Epagri, Ituporanga, SC.

\begin{tabular}{|c|c|c|c|c|c|c|}
\hline \multirow{2}{*}{$\begin{array}{l}\text { Fatores/variáveis } \\
\text { Preparo }\end{array}$} & \multicolumn{2}{|c|}{$\begin{array}{c}\text { PCT } \\
\text { t ha }\end{array}$} & \multicolumn{2}{|c|}{$\begin{array}{l}\text { Cx3+ } \\
\text { t ha' }\end{array}$} & \multicolumn{2}{|c|}{$\begin{array}{c}\text { PPC } \\
\%\end{array}$} \\
\hline & 2014* & 2015* & $2014 *$ & $2015 * *$ & $2014 * * *$ & 2015* \\
\hline Convencional & $21,72 b$ & $15,96 \mathrm{~b}$ & $4,76 \mathrm{~b}$ & - & - & $50,51 \mathrm{~ns}$ \\
\hline Plantio Direto & $23,64 a$ & 18,60 a & $10,19 a$ & 1,58 & - & 48,45 \\
\hline \multicolumn{7}{|l|}{ Tratamento } \\
\hline Conv & $35,30 a$ & $23,57 a$ & $14,02 \mathrm{a}$ & 4,58 & - & $75,25 a$ \\
\hline $\mathrm{rac} I$ & $27,41 \mathrm{~b}$ & $18,47 \mathrm{~b}$ & $4,19 \mathrm{~b}$ & 0,11 & - & $61,52 \mathrm{~b}$ \\
\hline rac II & $27,28 \mathrm{~b}$ & 19,07 b & $4,21 \mathrm{~b}$ & 0,06 & - & $66,72 a b$ \\
\hline org 1 & $17,66 \mathrm{c}$ & $14,29 \mathrm{c}$ & - & - & - & $33,51 \mathrm{c}$ \\
\hline org II & $17,37 \mathrm{c}$ & $15,45 \mathrm{bc}$ & - & - & - & $36,56 \mathrm{c}$ \\
\hline orglll & $16,43 \mathrm{c}$ & $14,92 \mathrm{bc}$ & - & - & - & $36,27 c$ \\
\hline orglV & $17,32 \mathrm{c}$ & $15,20 \mathrm{bc}$ & - & - & - & $36,51 \mathrm{c}$ \\
\hline Média & 22,68 & 17,28 & 7,48 & - & - & 49,48 \\
\hline CV (\%) & 11,85 & 15,47 & 34,49 & - & - & 15,72 \\
\hline
\end{tabular}

Médias seguidas pela mesma letra na coluna não diferem entre si, pelo teste de Tukey, a $5 \%$ de significância. ns = não significativo. * sem interação entre os fatores.

**dados sem distribuição normal (médias observadas). ***interação entre os fatores. Fonte: Autores.

Para os tratamentos verificou-se maior PCT para o tratamento convencional (conv), seguido dos tratamentos racionais (rac I e rac II) e orgânicos (org I, II, III e IV), que não diferiram estatisticamente entre si considerando cada grupo (racional e orgânico) (Tabela 3).

Na média dos anos agrícolas, os sistemas racionais rac I e rac II apresentaram em média PCTs $21,50 \%$ inferiores ao convencional (conv). Por sua vez, os sistemas de produção orgânicos revelaram produtividades comerciais 36,17\% e 45,38\% inferiores em relação à média dos sistemas convencionais (conv, rac I e rac II) e do sistema convencional (conv), respectivamente.

Em trabalhos similares, têm-se verificado que na região do Alto Vale do Itajaí (AVI), em anos com condições meteorológicas favoráveis ao desenvolvimento da cultura, os sistemas racionais podem ter a mesma capacidade produtiva de sistemas convencionais. Nesse sentido, Menezes Júnior et al. (2018), em 2013 em sistema de cultivo mínimo, verificaram produtividades médias de $38,06 \mathrm{t} \mathrm{ha}^{-1}$ para os tratamentos conv e rac II, ou seja, acima das observadas no presente estudo (Tabela 3). Tal fato, está relacionado possivelmente as condições meteorológicas da safra. Em 2013, registraram-se precipitações de $743,8 \mathrm{~mm}$, umidade relativa do ar média levemente inferior de $79,7 \%$ e, em especial, temperaturas médias mais amenas (temperatura mínima de $10,7 \circ \mathrm{O} C$, temperatura média de 15,5 으 $\mathrm{C}$ e temperatura máxima de 22,0 으) em relação as safras de 2014 e 2015 (Tabelas 2 e 3). 
Em geral, no AVI, a produtividade média da cebola em sistemas orgânicos tem sido de $20,50 \mathrm{t} \mathrm{ha}^{-1}$. (ALVES et al., 2017). No entanto, conforme o ano agrícola pode variar de 10,94 a 22,13 t ha-1. Normalmente, as produtividades obtidas para sistemas orgânicos em cultivo mínimo e preparo convencional têm sido, em média, 39,50\% inferiores aos tratamentos convencionais. (MENEZES JÚNIOR et al., 2014; MENEZES JÚNIOR et al., 2018). Esses dados são similares aos obtidos no presente trabalho, onde se verificou que na média dos anos de 2014 e 2015 a produtividade dos tratamentos orgânicos foi em média 40,78\% inferior aos demais.

As adubações diferenciais utilizadas entre os tratamentos rac I e rac II não influenciaram $(p>0,05)$ a PCT para ambos os anos agrícolas e sistemas de preparo do solo. Dessa forma, a PCT também foi similar entre os tratamentos orgânicos independente da dose de nitrogênio e a aplicação do preparado homeopático de calcário de conchas. Nesse sentido, ao se comparar os tratamentos racionais, o sistema rac I é mais econômico devido ao menor uso nitrogênio. Da mesma forma, entre os orgânicos, destaca-se o tratamento org I, pelo menor uso de nitrogênio e ausência do gasto com mão de obra com pulverização de calcário de conchas. Em ambos os casos, possivelmente, o aumento da adubação nitrogenada será vantajoso quando de condições meteorológicas mais favoráveis ao cultivo, como observado por Menezes Júnior et al. (2018). Convém ressaltar também que a produtividade de cebola em sistema orgânico com o uso de preparado homeopático de calcário de conchas pode ser incrementada em solo com alta fertilidade e adubação orgânica realizada previamente sobre a as plantas de cobertura. (GONÇALVES et al., 2009). No presente estudo, como toda adubação orgânica foi realizada durante o ciclo de plantio, provavelmente não houve tempo hábil para disponibilidade dos nutrientes pela lenta liberação dessa fonte.

A menores PCTs verificadas em 2015 estiveram relacionadas as condições meteorológicas da safra, notadamente em relação ao volume e regime diferencial de precipitação (Tabelas 2 e 3, Figuras 1 e 2). Observa-se que nos meses de setembro, outubro e novembro, correspondentes ao início da bulbificação, entumescimento ("enchimento") e maturação de bulbos, a precipitação foi decrescente para os meses em 2014 e excessiva em outubro e maior em novembro de 2015. Portanto, embora a fase de "enchimento" de bulbos é aquela em que ocorre a maior demanda hídrica pela cultura, excessos hídricos nessa fase aumentam a probabilidade de problemas fitossanitários e dificultam o manejo, ao reduzir a possibilidade de intervenção com produtos fitossanitários e sua eficiência. Além disso, aumentam a possibilidade de lixiviação de nutrientes, em especial, do nitrogênio. Nutriente mais acumulado pelas plantas de cebola, cuja maior demanda (73\%) ocorre nos dois terços finais do ciclo da cultura. (MENEZES JÚNIOR et al., 2014; KURTZ et al., 2016). Convém ressaltar, que durante as constantes precipitações pluviométricas a luminosidade necessária para a realização da atividade fotossintética normal para a cultura foi prejudicada.

\subsection{PRODUTIVIDADE DE ACORDO COM AS CLASSES DE BULBOS COMERCIAIS $(\mathrm{CX} 2, \mathrm{CX} 3 \mathrm{E} \mathrm{CX3+)}$}

Em 2014 e 2015, verificaram-se interações entre os fatores $(p>0,05)$ para a produtividade de bulbos da classe 2 (Cx2) e da classe 3 (Cx3). 
Em geral, observa-se que em sistema de plantio direto (PD), maiores produtividades Cx2 são observadas em ordem decrescente para os tratamentos orgânicos > racionais $>$ conv (Tabela 4).

Em 2014, as produtividades cx2 foram maiores nos tratamentos orgânicos em PC e PD (em média 14,25 $\mathrm{t} \mathrm{ha}^{-1}$ ). Contudo, para os tratamentos conv e racionais, a produtividade cx2 foi inferior em sistema de PD, sendo o mesmo observado em 2015, ano com excesso de precipitação na fase de enchimento de bulbos (Tabelas 2 e 4). Nesse ano, tal condição elevou a produtividade cx2 em sistema PC inclusive em conv, aproximando-a dos demais tratamentos. Como já mencionado o sistema PD melhora a condição física do solo, permitindo sob maior precipitação melhor infiltração da água, o que pode ter beneficiado a produtividade de bulbos de maior diâmetro.

Em anos sem fenômenos meteorológicos extremos, como 2014, não há diferenças significativas $(p>0,05)$ entre os tratamentos orgânicos para a produtividade $c \times 2$ (Tabela 5). No entanto, em 2015, observa-se que em PD a produtividade Cx2 foi superior em org I e org IV, respectivamente onde foi utilizada adubação com menor quantidade de nitrogênio e com maior quantidade de nitrogênio com calcário de conchas, Isso indica, que em condições de excesso hídrico utilizar doses baixas de nitrogênio de maneira isolada ou realizar aplicação foliar de preparado homeopático de calcário de conchas mesmo com altos doses de $\mathrm{N}$, pode não ser vantajoso do ponto de vista produtivo e econômico. Pois, houve incremento de bulbos menores expressos pela produtividade $\mathrm{C} \times 2$ nesses tratamentos. Além disso, a produtividade de bulbos cx3 não foi modificada, em geral, para os tratamentos orgânicos nos anos agrícolas (Tabela 5).

A maior formação de bulbos cx2 em sistemas orgânicos em relação aos convencionais e racionais tem sido observada, tanto PC quanto em PD e cultivo mínimo. (MENEZES JÚNIOR et al., 2014; MENEZES JÚNIOR, 2018). Cabe salientar que tal afirmação é válida para os sistemas de produção orgânicos preconizados em Santa Catarina, cuja adubação é, em geral, realizada com doses baixas de esterco de aves (EA) e fosfato natural (FN) seguindo, em geral, as recomendações da Comissão de Química e Fertilidade do Solo - RS/SC. (CQFS-RS/SC, 2004; CQFS-RS/SC, 2016). Nesse sentido, com base nessas fontes, doses de 75 a $125 \mathrm{~kg} \mathrm{~N}$ ha-1 e de $160 \mathrm{~kg} \mathrm{P}_{2} \mathrm{O}_{5}$ são equivalentes, considerando $1,0 \%$ de nitrogênio no $\mathrm{EA}$ e $9,0 \%$ de $\mathrm{P}_{2} \mathrm{O}_{5}$ solúvel em ácido cítrico no FN, a 7,50 e 12,50 t ha-1 de EA e 1,78 t ha-1 de FN.

Convém ressaltar, que dependendo das condições edafoclimáticas da localidade, do cultivar, dos manejos fitossanitário e de adubação podem ser obtidas altas produtividades em sistemas orgânicos. (BELFORT et al., 2006; COSTA et al., 2008; LEE, 2010). Por exemplo, Vidigal et al. (2010), em sistema orgânico, com o cultivar CNPH 6400, nas condições edafoclimáticas do estado de Minas Gerais, preconiza o uso de doses de $43 \mathrm{t} \mathrm{ha}^{-1}$ de composto orgânico a base de dejetos suínos $(2,24 \%$ de $\mathrm{N}$ e $0,67 \%$ de P) para a obtenção de PCT de $60,3 \mathrm{t} \mathrm{ha}^{-1}$, com produtividade cx2 abaixo de $1,7 \mathrm{t} \mathrm{ha}^{-1}$. 


\section{Revista Thema}

V.17

Tabela 4 - Interação dos tratamentos em relação ao sistema de preparo convencional (SC) e plantio direto (PD) para as variáveis classe $2(C \times 2)$, classe $3(C \times 3)$ e severidade de míldio em percentagem (SM\%) e perda pós-colheita em percentagem (PPC\%). Epagri, Ituporanga, SC.

\begin{tabular}{|c|c|c|c|c|}
\hline \multirow[t]{3}{*}{ Tratamento } & \multicolumn{4}{|c|}{$\begin{array}{c}\text { Cx2 } \\
\text { t ha-1 }\end{array}$} \\
\hline & \multicolumn{2}{|c|}{ PC } & \multicolumn{2}{|c|}{ PD } \\
\hline & 2014 & 2015 & 2014 & 2015 \\
\hline conv & $7,71 \mathrm{C}$ & $9,11 \mathrm{~b}$ & $3,40 \mathrm{c}$ & $4,76 \mathrm{c}$ \\
\hline rac I & $13,82 \mathrm{ab}$ & $11,95 a b$ & $6,80 \mathrm{~b}$ & $7,73 \mathrm{bc}$ \\
\hline rac II & $11,28 \mathrm{~b}$ & $12,07 \mathrm{ab}$ & $5,75 \mathrm{bc}$ & $7,95 \mathrm{~b}$ \\
\hline org I & 15,17 a & $10,96 \mathrm{ab}$ & $14,44 \mathrm{a}$ & $13,63 a$ \\
\hline org II & $14,68 \mathrm{a}$ & $11,90 \mathrm{ab}$ & $14,56 \mathrm{a}$ & $12,56 \mathrm{a}$ \\
\hline org III & $13,86 a b$ & $12,21 \mathrm{a}$ & $13,48 a$ & $12,69 \mathrm{a}$ \\
\hline org IV & $14,65 \mathrm{a}$ & $12,03 a b$ & $13,19 a$ & $14,12 \mathrm{a}$ \\
\hline Média & 13,02 & 11,48 & 10,23 & 10,06 \\
\hline \multirow[t]{4}{*}{ CV (\%) } & 12,48 & 12,83 & 12,48 & 12,83 \\
\hline & \multicolumn{4}{|c|}{ Cx3 } \\
\hline & \multicolumn{2}{|c|}{ PC } & \multicolumn{2}{|c|}{ PD } \\
\hline & 2014 & 2015 & 2014 & 2015 \\
\hline conv & 17,18 a & $13,27 a$ & $14,28 \mathrm{a}$ & $15,35 a$ \\
\hline $\mathrm{racl}$ & $8,98 \mathrm{~b}$ & 5,22 bc & $16,84 \mathrm{a}$ & 11,93 a \\
\hline rac II & $12,94 \mathrm{ab}$ & $6,46 \mathrm{~b}$ & $16,17 \mathrm{a}$ & $11,60 \mathrm{a}$ \\
\hline org I & $2,22 \mathrm{c}$ & $0,93 d$ & $3,49 \mathrm{~b}$ & $3,05 b$ \\
\hline org II & $1,20 \mathrm{c}$ & $1,98 \mathrm{~cd}$ & $4,29 \mathrm{~b}$ & $4,46 \mathrm{~b}$ \\
\hline org III & $2,13 \mathrm{c}$ & $2,10 \mathrm{~cd}$ & $3,40 \mathrm{~b}$ & $2,83 \mathrm{~b}$ \\
\hline org IV & $2,00 \mathrm{C}$ & $1,50 \mathrm{~cd}$ & $4,81 \mathrm{~b}$ & $2,75 \mathrm{~b}$ \\
\hline Média & 6,67 & 4,49 & 9,04 & 7,42 \\
\hline CV (\%) & 29,49 & 29,58 & 29,49 & 29,58 \\
\hline \multirow[t]{3}{*}{ Tratamento } & \multicolumn{4}{|c|}{ SM\% } \\
\hline & \multicolumn{2}{|c|}{ PC } & \multicolumn{2}{|c|}{ PD } \\
\hline & 2014 & 2015 & 2014 & 2015 \\
\hline conv & $24,55 \mathrm{c}$ & $31,45 \mathrm{~b}$ & $42,50 \mathrm{c}$ & $21,93 \mathrm{c}$ \\
\hline $\mathrm{racl}$ & 28,05 bc & $42,85 a$ & $47,30 \mathrm{bc}$ & $30,73 b$ \\
\hline rac II & $36,05 a$ & $42,85 \mathrm{a}$ & 48,79 bc & $31,85 \mathrm{~b}$ \\
\hline org I & $34,28 a b$ & 48,98 a & $57,55 a$ & $46,10 a$ \\
\hline org II & $31,28 \mathrm{abc}$ & $44,88 \mathrm{a}$ & 59,52 a & $49,20 \mathrm{a}$ \\
\hline org III & $33,55 \mathrm{ab}$ & $45,05 a$ & $54,92 a b$ & 44,68 a \\
\hline org IV & $29,50 \mathrm{abc}$ & $46,50 \mathrm{a}$ & 57,98 a & $46,05 \mathrm{a}$ \\
\hline Média & 31,04 & 43,22 & 52,65 & 38,65 \\
\hline CV $(\%)$ & 8,47 & 8,04 & 8,47 & 8,04 \\
\hline
\end{tabular}

Médias seguidas pela mesma letra na coluna não diferem entre si, pelo teste de Tukey, a $5 \%$ de significância. ns = não significativo.

Fonte: Autores.

É importante salientar que segundo Menezes Júnior e Vieira Neto (2012), a produtividade de cx2 é indesejada em sistemas convencionais de produção, pois no mercado bulbos com tal classificação recebem a metade do valor pago em relação aos bulbos de maior diâmetro transversal (bulbos classe 3 e superiores, com diâmetro transversal acima de $50 \mathrm{~mm}$ ). Por sua vez, independente do diâmetro transversal, não há diferenciação de preço pago ao produtor por bulbos de cebola produzidos em sistemas orgânicos, o que é uma vantagem. 
Tabela 5 - Interação entre sistemas de preparo convencional (SC) e plantio direto (PD) em relação aos tratamentos (conv, rac I, rac II, org I, org II, org III e org IV) para as variáveis classe $2(\mathrm{C} \times 2)$, classe $3(\mathrm{C} \times 3)$, severidade de míldio em percentagem

(SM\%) e perda pós-colheita em percentagem (PPC\%). Epagri, Ituporanga, SC.

\begin{tabular}{|c|c|c|c|c|c|c|c|}
\hline \multirow[t]{2}{*}{ Fatores } & \multicolumn{2}{|c|}{ CX 2} & \multicolumn{2}{|c|}{ CX 3} & \multicolumn{2}{|c|}{ SM \% } & \multirow{2}{*}{$\begin{array}{c}\text { PPC \% } \\
2014\end{array}$} \\
\hline & 2014 & 2015 & 2014 & 2015 & 2014 & 2015 & \\
\hline $\begin{array}{l}\text { Preparo x Conv } \\
\text { SC } \\
\text { PD }\end{array}$ & $\begin{array}{l}7,71 \mathrm{a} \\
3,39 \mathrm{~b}\end{array}$ & $\begin{array}{l}9,11 \mathrm{a} \\
4,76 \mathrm{~b}\end{array}$ & $\begin{array}{l}17,18 \text { ns } \\
14,28\end{array}$ & $\begin{array}{l}13,27 \mathrm{~ns} \\
15,34\end{array}$ & $\begin{array}{l}24,55 \mathrm{~b} \\
42,50 \mathrm{a}\end{array}$ & $\begin{array}{l}31,45 \mathrm{a} \\
21,93 \mathrm{~b}\end{array}$ & $\begin{array}{l}38,84 \text { ns } \\
38,07\end{array}$ \\
\hline $\begin{array}{l}\text { Preparo x rac I } \\
\text { SC } \\
\text { PD }\end{array}$ & $\begin{array}{c}13,82 \mathrm{a} \\
6,80 \mathrm{~b}\end{array}$ & $\begin{array}{r}11,95 \mathrm{a} \\
7,73 \mathrm{~b}\end{array}$ & $\begin{array}{r}8,98 \mathrm{~b} \\
16,83 \mathrm{a}\end{array}$ & $\begin{array}{r}5,22 \mathrm{~b} \\
11,93 \mathrm{a}\end{array}$ & $\begin{array}{l}28,05 \mathrm{~b} \\
47,30 \mathrm{a}\end{array}$ & $\begin{array}{l}42,85 \mathrm{a} \\
30,73 \mathrm{~b}\end{array}$ & $\begin{array}{l}38,69 \text { ns } \\
46,99\end{array}$ \\
\hline $\begin{array}{l}\text { Preparo x rac II } \\
\text { SC } \\
\text { PD }\end{array}$ & $\begin{array}{c}11,28 a \\
5,75 b\end{array}$ & $\begin{array}{r}12,07 \mathrm{a} \\
7,95 \mathrm{~b}\end{array}$ & $\begin{array}{l}12,94 \mathrm{~ns} \\
16,17\end{array}$ & $\begin{array}{r}6,46 \mathrm{~b} \\
11,60 \mathrm{a}\end{array}$ & $\begin{array}{l}36,05 \mathrm{~b} \\
48,79 \mathrm{a}\end{array}$ & $\begin{array}{l}42,85 \mathrm{a} \\
31,85 \mathrm{~b}\end{array}$ & $\begin{array}{l}37,90 \mathrm{~b} \\
55,28 \mathrm{a}\end{array}$ \\
\hline $\begin{array}{l}\text { Preparo } \times \text { org I } \\
\text { SC } \\
\text { PD }\end{array}$ & $\begin{array}{l}15,17 \text { ns } \\
14,44\end{array}$ & $\begin{array}{l}10,96 \mathrm{~b} \\
13,63 \mathrm{a}\end{array}$ & $\begin{array}{l}2,22 \mathrm{~ns} \\
3,49\end{array}$ & $\begin{array}{l}0,93 \mathrm{~ns} \\
3,05\end{array}$ & $\begin{array}{l}34,28 \mathrm{~b} \\
57,55 \mathrm{a}\end{array}$ & $\begin{array}{l}48,98 \mathrm{~ns} \\
46,10\end{array}$ & $\begin{array}{l}38,49 \mathrm{a} \\
22,77 \mathrm{~b}\end{array}$ \\
\hline $\begin{array}{l}\text { Preparo } \times \text { org II } \\
\text { SC } \\
\text { PD }\end{array}$ & $\begin{array}{l}14,68 \text { ns } \\
14,56\end{array}$ & $\begin{array}{l}11,90 \text { ns } \\
12,58\end{array}$ & $\begin{array}{l}1,20 \text { ns } \\
4,29\end{array}$ & $\begin{array}{l}1,98 \text { ns } \\
4,46\end{array}$ & $\begin{array}{l}31,28 \mathrm{~b} \\
59,52 \mathrm{a}\end{array}$ & $\begin{array}{l}44,88 \text { ns } \\
49,20\end{array}$ & $\begin{array}{l}32,16 \text { ns } \\
26,70\end{array}$ \\
\hline $\begin{array}{l}\text { Preparo } \times \text { org III } \\
\text { SC } \\
\text { PD }\end{array}$ & $\begin{array}{l}13,86 \text { ns } \\
13,48\end{array}$ & $\begin{array}{l}12,21 \mathrm{~ns} \\
12,69\end{array}$ & $\begin{array}{l}2,12 \text { ns } \\
3,39\end{array}$ & $\begin{array}{l}2,10 \mathrm{~ns} \\
2,83\end{array}$ & $\begin{array}{l}33,55 \mathrm{~b} \\
54,92 \mathrm{a}\end{array}$ & $\begin{array}{l}45,05 \text { ns } \\
44,68\end{array}$ & $\begin{array}{l}35,34 \text { ns } \\
25,69\end{array}$ \\
\hline $\begin{array}{l}\text { Preparo } \times \text { org IV } \\
\text { SC } \\
\text { PD }\end{array}$ & $\begin{array}{l}14,65 \text { ns } \\
13,19\end{array}$ & $\begin{array}{l}12,03 \mathrm{~b} \\
14,12 \mathrm{a}\end{array}$ & $\begin{array}{l}1,99 \text { ns } \\
4,80\end{array}$ & $\begin{array}{l}1,50 \mathrm{~ns} \\
2,75\end{array}$ & $\begin{array}{l}29,50 \mathrm{~b} \\
58,00 \mathrm{a}\end{array}$ & $\begin{array}{l}46,05 \mathrm{~ns} \\
46,50\end{array}$ & $\begin{array}{l}29,35 \mathrm{~ns} \\
22,04\end{array}$ \\
\hline $\begin{array}{l}\text { Média } \\
\text { CV(\%) }\end{array}$ & $\begin{array}{l}11,56 \\
12,48\end{array}$ & $\begin{array}{l}10,98 \\
12,83\end{array}$ & $\begin{array}{l}7,85 \\
29,49\end{array}$ & $\begin{array}{l}5,96 \\
29,58\end{array}$ & $\begin{array}{l}41,85 \\
8,47\end{array}$ & $\begin{array}{l}40,94 \\
8,04\end{array}$ & 23,80 \\
\hline
\end{tabular}

Médias seguidas pela mesma letra na coluna não diferem entre si, pelo teste de Tukey, a 5\% de significância. ns = não significativo.

Fonte: Autores.

Por sua vez, em média, a produtividade de bulbos cx3 foi maior em sistema PD em relação ao PC em ambos os anos agrícolas para todos os tratamentos, na média dos tratamentos a produtividade cx3 foi 47,49\% superior em PD (Tabelas 4 e 5). Em geral, para ambos os sistemas de preparo (PC e PD) as maiores produtividades de bulbos cx3 foram observadas, para os tratamentos conv, rac I e rac II, e menores para os orgânicos.

Em 2014, a produtividade cx3 em PC do tratamento rac II não diferiu do conv (média de 15,06 t ha-1) e no PD não diferiu entre conv, rac I e rac II (média de 15,76 t ha ${ }^{-1}$ ). Em 2015, ano com excesso hídrico, as produtividades cx3 foram maiores nos tratamentos conv, rac I e rac II em sistema de PD, enquanto em PC a média do conv foi superior aos demais tratamentos $\left(13,27 \mathrm{t} \mathrm{ha}^{-1}\right.$ ) em relação aos racionais (média de 5,84 $\left.\mathrm{t} \mathrm{ha}^{-1}\right)$. Para os tratamentos orgânicos, em que não foram observadas diferenças significativas $(p>0,05)$, as produtividades médias cx3 foram em 2014 de $1,89 \mathrm{t} \mathrm{ha}^{-1}$ 
em PC e de 4,05 t ha-1 em PD, e em 2015 de 1,63 t ha-1 em PC e de 3,27 t ha-1 em PD. A produtividade média em tratamentos orgânicos foi $52 \%$ superior em sistema PD.

Portanto, o sistema de plantio direto aumentou a produtividade de bulbos da classe 3 . $\mathrm{Na}$ maioria dos casos o tratamento rac II atinge produtividades similares ao tratamento conv. Menezes Júnior et al. (2018), em sistema de cultivo mínimo com tratamentos similares, observou que em anos sem eventos climáticos extremos a produtividade de bulbos cx3 não difere entre o tratamento convencional e sistemas racionais, obtendo produtividades cx3 médias de 25,85 $t$ ha ${ }^{-1}$. No presente experimento, embora as produtividades sejam menores, verificam-se os benefícios do uso do PD, mesmo em ano com excesso hídrico.

Em relação aos tratamentos orgânicos a escolha do sistema de plantio direto juntamente com o tratamento org I parece ser mais indicada, devido a obtenção das mesmas produtividades PCT, cx2, cx3 com menor gasto de insumos (adubo orgânico, e preparado homeopático) e mão-de-obra (custo da aplicação do preparado homeopático de calcário de conchas). Isso se deve à ausência de diferenças significativas em relação as produtividades em sistema de plantio direto, que se encontram provavelmente relacionadas a menor taxa de mineralização do nitrogênio, sob maior umidade e temperaturas mais amenas do solo neste sistema.

Em 2014 e 2015, a maior formação de bulbos cx3+ (diâmetro transversal > de 70 $\mathrm{mm}$ ) foi observada em sistema de PD (Tabela 3), na média 2,5 vezes superior à observada em PC, considerando os tratamentos conv e rac I e rac II. A produtividade cx3+ foi maior em conv em relação aos tratamentos rac I e rac II. Não houve a formação de bulbos acima da classe 3 para os tratamentos orgânicos. Verifica-se que em anos de estresse hídrico, além da menor produtividade, a ausência de formação de bulbos cx3+. Provavelmente, a aceleração do desenvolvimento inicial devido a temperaturas mais elevadas no início do ciclo associadas a maiores precipitações no período de desenvolvimento e maturação dos bulbos foram responsáveis pela menor produtividade cx3+ em 2015, sendo atenuada em PD (Tabelas 2 e 3). Em sistema orgânico, Santos et al. (2012) atribuíram o efeito benéfico da cobertura morta na produtividade e na qualidade da cebola à manutenção de maior umidade e da redução da amplitude térmica do solo. No presente experimento, a manutenção de plantas de cobertura auxiliou de diversas formas as produtividades, em especial, no ano de 2015, ao diminuir a severidade de míldio, reduzir a incidência de tripes, e, provavelmente, garantir a maior percolação da água sob excesso hídrico.

A formação menor de bulbos cx3+ nos sistemas de produção orgânicos utilizados no AVI em relação aos convencionais, tem sido verificada em diversos trabalhos, notadamente em anos com estresses hídricos e com alta severidade de míldio e, em geral, em solo sem plantas de cobertura. (SANTOS et al., 2012; MENEZES JÚNIOR et al., 2014; MENEZES JÚNIOR et al., 2018).

\subsection{SEVERIDADE DE MÍLDIO (SM\%)}

Em relação a severidade de míldio (SM\%) observou-se interações significativas $(p>0,05)$ entre os fatores para ambos os anos experimentais (Tabelas 4 e 5). 
Em 2014, maiores SM\% foram observadas para o sistema de plantio direto, PD (média de 52,65\%) em relação ao plantio convencional, PC (média de 31,04\%). De forma inversa, em 2015, ano com maior precipitação pluviométrica total, maiores SM\% foram registradas para PC (média 43,22\%) em relação ao PD (média 38,65\%) (Tabelas 4 e 5). Nesse ano, entretanto, não houve diferenças significativas $(p>0,05)$ entre os sistemas de preparo do solo para os tratamentos orgânicos, sendo as maiores SM\% observadas em PC para tratamentos conv, rac I e rac II (média de 39,05\%) em relação ao PD $(28,17 \%)$ (Tabela 5).

Portanto, em relação ao sistema de preparo do solo (SPS), em ano com precipitação menor (632,6 mm, em 2014), a severidade de míldio foi maior em PD. Por sua vez, em ano com precipitação maior $(813,2 \mathrm{~mm}$, em 2015) o SPS não interferiu na SM\% em sistemas orgânicos, sendo menor em PD para tratamentos com uso de adubos minerais e fungicidas convencionais (conv, rac I e rac II).

Em 2014, ao considerar os tratamentos em PC, observam-se SM\% similares, com a tendência geral da SM\% decrescer de rac II, orgânicos, rac I e conv. Por sua vez em PD, a tendência foi maior severidade para os tratamentos orgânicos $(57,50 \%)$, e menores para os demais tratamentos (46,20\%). Exceto para o org III cuja SM\% foi similar a rac I e rac II. Em 2015, ano de maior precipitação pluviométrica, no PC a menor SM\% foi verificada para o tratamento conv $(31,45 \%)$, não diferindo para os demais tratamentos (média de 45,19\%). Enquanto no ano de 2015 em PD, a SM\% decresceu dos tratamentos orgânicos (média de 46,51\%), para os racionais (média de $31,29 \%$ ) e convencional (21,93\%) (Tabela 4 ). Portanto, verifica-se que em anos de maior precipitação (eventos meteorológicos extremos) o sistema de PD reduz a severidade de míldio, mas em anos de precipitação menor e mais bem distribuída ocorre o inverso (Tabela 4). Isso se deve à ausência de esporulação para novos sítios de infecção em decorrência da remoção dos esporângios pelo impacto das gotas da chuva nas folhas. (HILDEBRAND; SUTTON, 1982; MARCUZZO et al., 2017).

Em geral, o tratamento fitossanitário realizado em sistemas convencional foi mais eficiente em reduzir a severidade de míldio (média de $30,11 \%$ ), seguido dos racionais (média de 38,56\%) e orgânicos (45,63\%). Nesse sentido, ao comparar a aplicação de oxicloreto de cobre em aplicação quinzenal trinta dias após o transplante realizada nos tratamentos orgânicos (com o sem o uso de calcário de conchas) com o uso de fungicida protetor alternado com curativo aplicados um mês após o transplante utilizado em rac I e rac II, ocorreu uma redução em $15,5 \%$ da SM\%, ou seja, os tratamentos racionais foram $15,5 \%$ mais eficientes em relação aos orgânicos. Por sua vez, ao se comparar o tratamento fitossanitário convencional, em que se utilizou apenas fungicidas curativos de diferentes princípios ativos aplicados de forma alternada, verifica-se a redução em $34,0 \%$ na SM\%, ou seja, o tratamento convencional foi $34 \%$ mais eficiente que os orgânicos. De forma correspondente, ao se comparar o tratamento fitossanitário convencional com os racionais, observa-se que esses são em média 22,0\% menos eficientes em relação ao convencional. Marcuzzo et al. (2016) observaram que a severidade final em sistemas racionais não diferiram estatisticamente do convencional em dois anos de avaliação, mas todos diferiram do sistema orgânico. 
Na média dos anos a produtividade comercial total $\left(\mathrm{PCT}_{\text {média }}\right.$ ) e a formação de bulbos cx3 $+_{\text {média }}$ estiveram negativamente correlacionadas a SM\% $\left(r_{\text {pctmédia }}=-0,79 ; r_{\mathrm{cx} 3+\text { média }}=-\right.$ 0,56), indicando que a severidade de míldio reduz a $P C T_{\text {média }}$ e a formação de bulbos cx3+média. É importante mencionar que nos tratamentos orgânicos não houve a formação de bulbos cx3+, ou seja, bulbos de diâmetro transversal acima de $70 \mathrm{~mm}$ e que não houve correlação entre $c x 2$ e a severidade média de míldio. Marcuzzo et al. (2016) constaram que a PCT foi superior no sistema convencional, mas o uso de sistemas racionais foram estaticamente superiores ao sistema orgânico de produção.

\subsection{INCIDÊNCIA DE TRIPES (IT)}

As notas médias de incidência de tripes entre os sistemas de plantio, convencional (SC) e plantio direto (PD) em 2014 e 2015, foram respectivamente, SC=1,43 e 1,21 e $\mathrm{PD}=1,20$ e 1,04, e diferiram entre si de maneira extremamente significativa, pelo teste de $T$, com valores de $T=3,60$ e 4,38, $G L=138$ e 278, e com $p<0,0004$ e 0,0001. Portanto, em sistema de manejo convencional de solo a incidência de tripes foi superior ao de plantio direto, o que sugere que a manutenção de plantas de cobertura reduziu a incidência de tripes nas áreas experimentais. A presença de palha sobre a superfície do solo desfavorece a incidência de tripes por controle mecânico de pupas no solo. (LARENTZAKI et al., 2008).

O sistema de plantio direto na palha em cebola pode aumentar a tolerância das plantas aos danos de tripes. (GONÇALVES, 2016; SCHWARTZ et al., 2009; MADEIRA et al., 2013). Isso pode ter colaborado para a superioridade da produtividade de cebola em sistema de plantio direto em relação ao convencional. Em manejo de solo convencional com revolvimento ocorre correlação negativa entre a produtividade de cebola e a incidência de tripes. (GONÇALVES; VIEIRA NETO, 2011; MENEZES JÚNIOR et al., 2014).

Convém ressaltar que os níveis de incidência foram relativamente baixos e inferiores ao nível de dano econômico, nota 3 da escala visual utilizada na avaliação. (GONÇALVES et al., 2014). Isso ocorreu provavelmente pelo uso do cultivar Bola Precoce, que se desenvolve em períodos de temperatura mais amena com escape a altas densidades populacionais do inseto. (GONÇALVES, 2016). Outro aspecto a considerar é que em nenhum dos anos agrícolas houve diferenças entre os tratamentos aplicados para a incidência de tripes. Isso provavelmente deve-se a condição de plantio antecipado das cultivares precoces, que é uma estratégia de controle cultural do inseto em condições climáticas normais. (GONÇALVES, 2016).

Em relação aos anos agrícolas, a maior incidência de tripes foi observada em 2014 (média de 1,32) em relação a 2015 (média de 1,13). Isso foi devido às temperaturas mais elevadas, menor precipitação e UR\% ocorrentes no período de outubro a novembro de 2014. Segundo Gonçalves (2016), a incidência de tripes é incrementada pela temperatura e menores precipitações pluviométricas. Dessa forma, altas densidades populacionais de tripes em cebola são verificadas em períodos quentes e secos. (WAIGANJO et al., 2008; GONÇALVES, 2016). No Alto Vale do Itajaí, tal condição ocorre principalmente nos meses outubro a novembro quando a temperatura média acima de $20^{\circ} \mathrm{C}$ (GONÇALVES, 2016), o que foi verificado em 2014 (Tabela 2). 


\subsection{FLORESCIMENTO (FLORESC\%) E PERDAS EM PÓS-COLHEITA (PPC\%)}

Em 2014, maiores percentagens de florescimento (Floresc\%) foram observados em sistema de PD $(1,35 \%)$ em relação ao PC $(0,44 \%)$, em especial, nos tratamentos conv $(2,43 \%)$ e rac I (1,37\%). Nos demais tratamentos o florescimento foi em média de 0,49\%. Em 2015, o florescimento ocorreu apenas no sistema de PD, sendo de 3,79\% em conv, 3,74\% em rac I, 2,66 em rac II, e na média dos tratamentos orgânicos de $0,97 \%$. Portanto, o sistema de PD, provavelmente, ao manter a umidade e reduzir a temperatura do solo, predispôs as plantas ao maior florescimento, em especial, em tratamentos convencionais e racionais. Ao considerar as características do cultivar Bola Precoce, cujo florescimento esperado é inferior a 1\% (GANDIN et al., 1986), o Floresc\% observado pode ser considerada elevado nos tratamentos conv, rac I e rac II. Por sua vez, os trabalhos desenvolvidos no AVI indicam menor florescimento em sistemas orgânicos de produção. (MENEZES JúNIOR et al., 2014; MENEZES JÚNIOR et al., 2018).

Em 2014, houve interação $(p>0,05)$ entre os fatores para a percentagem de perdas em pós-colheita após 4 meses de armazenamento (PPC\%). Em solo com preparo convencional as perdas foram, em média, de $35,68 \%$ não diferindo para os tratamentos (Tabela 6). No plantio direto (PD), observam-se em geral menor PPC\% em relação ao PC, em média, 33,93\%. Os valores de PPC\% foram menores nos cultivos orgânicos em relação aos tratamentos racionais. O tratamento conv se situou em situação intermediária e com a PPC\% similar aos tratamentos racionais (Tabela 6).

A PPC\% em análise por sistema de preparo do solo apresentou diferenças significativas para rac II e org I (Tabela 5). A PPC\% para rac II foi maior em PD $(55,28 \%)$ em relação ao PC (37,90\%). Enquanto que, APPC\% para org I foi maior em PC $(38,49 \%)$ que no PD $(22,77 \%)$. No tratamento rac II é possível que a adição da maior quantidade de nitrogênio na forma mineral, associado a diminuição da proteção foliar pelo menor uso de produtos fitossanitários e a predisposição a ocorrência de bacterioses pela maior umidade do solo tenham contribuído para a maior PPC\% em PD. Enquanto que no tratamento org I a disponibilização mais lenta do nitrogênio em formas orgânicas em PD favoreceu menor PPC\% em comparação ao PC.

Em 2015, não foi observada interação entre os fatores $(p>0,05)$ para PPC\%. Nesse caso, devido ao excesso de chuvas, não houve diferenças entre os sistemas de preparo do solo com PPC\%, média em torno de 50\%. Para os tratamentos, observa-se que a maior perda ocorre para o conv $(75,25 \%)$. A PPC\% do rac II $(66,72 \%)$ foi similar ao conv, e a do rac I $(61,52 \%)$ inferior ao conv. As menores perdas em pós-colheita foram observadas nos tratamentos orgânicos (média de 35,71\%).

Os dados indicam que em 2014, ano com menor precipitação no período de outubro e novembro, menores perdas pós-colheita são observadas em sistema de plantio direto, com o uso de doses menores de nitrogênio o do fornecimento do nitrogênio em doses maiores em sistemas orgânicos, onde o nitrogênio é disponibilizado aos poucos às plantas. Em ano chuvoso, o sistema de preparo do solo não interfere nas PPC\%, mas permanece elevado em tratamentos em que as doses de nitrogênio são maiores e fornecidas na forma mineral, como em 2015 (Tabela 3). 
Tabela 6 - Interação dos tratamentos em relação ao sistema de preparo convencional (SC) e plantio direto (PD) para a variável perda pós-colheita em percentagem (PPC\%).

Epagri, Ituporanga, SC.

\begin{tabular}{lccccc}
\hline \multicolumn{2}{c}{ Tratamento } & \multicolumn{5}{c}{ PPC\% } & PC & & \\
\hline & $\mathbf{2 0 1 4}$ & $\mathbf{2 0 1 5}$ & $\mathbf{2 0 1 4}$ & $\mathbf{2 0 1 5}$ \\
\hline conv & $38,84 \mathrm{~ns}$ & - & $38,07 \mathrm{ab}$ & - \\
rac I & 38,69 & - & $46,99 \mathrm{a}$ & - \\
rac II & 37,90 & - & $55,28 \mathrm{a}$ & - \\
org I & 38,49 & - & $22,76 \mathrm{~b}$ & - \\
org II & 32,16 & - & $26,70 \mathrm{~b}$ & - \\
org III & 34,35 & - & $25,70 \mathrm{~b}$ & - \\
org IV & 29,35 & - & $22,04 \mathrm{~b}$ & - \\
Média & 35,68 & - & 33,93 & - \\
CV (\%) & 23,80 & - & 23,80 & - \\
\hline
\end{tabular}

Médias seguidas pela mesma letra na coluna não diferem entre si, pelo teste de Tukey, a $5 \%$ de significância. ns = não significativo.

Fonte: Autores.

Diversos autores indicam que as perdas em pós-colheita, independente do sistema de preparo do solo e fonte, estão associadas ao excesso de precipitação e ao aumento de doses de nitrogênio. (KURTZ et al., 2013; MENEZES JÚNIOR et al., 2013; MENEZES JÚNIOR et al., 2014; HIGASHIKAWA; MENEZES JÚNIOR, 2017; MENEZES JÚNIOR et al., 2018). De acordo com Wordell Filho e Boff (2006), o excesso de chuvas aliado a temperaturas mais elevadas, favorece a incidência de doenças bacterianas que são as principais responsáveis pelo apodrecimento dos bulbos durante o armazenamento. Nesta condição, Wordell Filho e Boff (2006) sugerem que quando o objetivo for armazenar os bulbos, a redução das doses de nitrogênio na lavoura como medida para reduzir as perdas pós-colheita.

O presente estudo indica que as maiores perdas em pós-colheita ocorrem em sistema de preparo convencional. A PPC\% é superior em anos com excesso hídrico em especial no período de outubro a novembro (período de desenvolvimento e maturação dos bulbos), com doses maiores de nitrogênio na forma mineral, que é mais facilmente lixiviável.

\section{CONCLUSÕES}

O cultivo em sistema de plantio direto aumenta a produtividade comercial total e de cx3 em relação ao manejo convencional de solo. A formação de bulbos cx3+ é observada apenas nos tratamentos convencional e racionais, é maior em PD. A produtividade total e cx3+ são superiores em tratamento convencional. A produtividade cx3 é similar entre tratamentos convencional e racionas II em PD. Os bulbos de diâmetros menores, cx2, são observadas nos tratamentos orgânicos. A severidade de míldio foi superior em tratamentos orgânicos>racionais $>$ conv. $O$ manejo fitossanitário utilizado no tratamento conv é mais eficiente na redução da SM \% em relação ao realizado nos tratamentos racionais e orgânicos. O manejo fitossanitário empregado nos tratamentos racionais é mais eficiente na redução da SM \% em relação ao utilizado nos tratamentos orgânicos. A incidência de tripes é menor em sistema de PD. O florescimento é maior em sistema de PD. Maiores PPC (\%) 
ocorrem em sistema de preparo convencional, em especial, em anos com excesso hídrico no período de desenvolvimento e maturação dos bulbos.

\section{REFERÊNCIAS BIBLIOGRÁFICAS}

ALTMANN, N. Plantio direto no cerrado: 25 anos acreditando no sistema. Passo Fundo: Aldeia Norte Editora, 2010.

ALVES, D. P.; WAMSER, G. E.; KURTZ, C.; GONÇALVES, P. A. S.; MENEZES JÚNIOR, F. O. G. Cebola. In: Avaliação de cultivares para o estado de Santa Catarina 2017-2018 (Boletim Técnico, 176). 1. ed. Florianópolis: Departamento Estadual de Marketing e Comunicação (DEMC) / Epagri, 2017. p.31-33.

BAYER, C.; MIELNICZUK, J.; SANTOS, S. R. Física do solo, diagnóstico e manejo da compactação em plantio direto. p.175-202. In: Manejo e fertilidade de solos em plantio direto. FONTOURA, S. M.V.; BAYER, C. 2. ed. Guarapuava: Fundação Agrária de Pesquisa Agropecuária, 2009.

BELFORT, G.; NAKADA, P. G.; SILVA, D. J. H.; DANTAS, G. G.; SANTOS, R. R.H. Desempenho de cultivares de cebola nos sistemas orgânico e convencional em Minas Gerais. Horticultura Brasileira, Brasília, v.24, n.2, p.206-209, abr.-jun. 2006.

COSTA, N. D.; ARAUJO, J. F.; SANTOS, C. A. F.; RESENDE, G. M.; LIMA, M. A. C. Desempenho de cultivares de cebola em cultivo orgânico e tipos de solo no Vale do São Francisco. Horticultura Brasileira, Brasília, v.26, n.4, p.476-480, out.-dez. 2008.

CQFS - RS/SC - COMISSÃO DE QUÍMICA E FERTILIDADE DO SOLO RS/SC - CQFS-RS/SC. Manual de adubação e de calagem para o Estado do Rio Grande do Sul e Santa Catarina. Porto Alegre: UFRGS, 2004.

CQFS - RS/SC - COMISSÃO DE QUÍMICA E FERTILIDADE DO SOLO RS/SC - CQFS-RS/SC. Manual de adubação e de calagem para o Estado do Rio Grande do Sul e Santa Catarina. Santa Maria: SBCS/Núcleo Regional Sul, 2016.

EPAGRI. 2013. Sistema de produção para a cebola - Santa Catarina.

Florianópolis: Epagri. (Sistemas de Produção n.46).

GANDIN, C. L.; YOKOYAMA, S.; THOMAZELLI, L. F.; GUIMARÃES, D. R.; BIASI, J; BECKER, W. F.; FAORO, I. D.; NETO, J. A. Z.; PIANA, Z; MÜLLER, J. J. V.; SILVA, A. C. F.; VIZZOTTO, V. J. Nova cultivar de cebola de ciclo médio para SC. Agropecuária Catarinense, v.2, p.40-42, 1989.

GONÇALVES, P. A. S.; BOFF, P.; BOFF, M. I. C. Influência do preparado homeopático de calcário de conchas sobre tripes e produtividade de cebola. Agropecuária

Catarinense, Florianópolis, v.22, n.1, p.91-93, 2009.

GONÇALVES, P. A. S.;VIEIRA NETO, J. Influência da incidência de tripes, Thrips tabaci Lind. (Thysanoptera: Thripidae) na produtividade de cebola em sistemas convencional e orgânico. Revista Brasileira de Agroecologia, Porto Alegre, v.6, n.2, p.152-158, 2011. 
GONÇALVES, P. A. S.; BOFF, P.; MENEZES JÚNIOR, F. O. G. Efeito de altas diluições de calcário de conchas e Natrum muriaticum no manejo fitossanitário, na produtividade e na armazenagem de cebola em sistema orgânico. Agropecuária Catarinense, v.27, n.3, p.78-82, 2014.

GONCALVES, P. A. S. Manejo de pragas. In: MENEZES JÚNIOR, F. O. G.; MARCUZZO, L. L. (Eds.). Manual de prática agrícolas: guia para a sustentabilidade das lavouras de cebola do estado de Santa Catarina. 1. ed. Florianópolis: Departamento Estadual de Marketing e Comunicação (DEMC) / Epagri, 2016. p.81-90.

HIGASHIKAWA, F. S.; MENEZES JÚNIOR, F. O. G. Adubação mineral, orgânica e organomineral: efeitos na nutrição, produtividade, pós-colheita da cebola e na fertilidade do solo. Revista Scientia Agraria, v.18, p.1-10, 2017.

HILDEBRAND, P. D.; SUTTON, J. C. Weather variables in relation to epidemic of downy mildew. Phytopathology, St. Paul, v.72, n.3, p.219-224, 1982.

KURTZ, C.; ERNANI, P. R.; PAULETTI, V.; MENEZES JÚNIOR, F. O. G.; VIEIRA NETO, J. Produtividade e conservação de cebola afetadas pela adubação nitrogenada no sistema de plantio direto. Horticultura Brasileira, v.31, p.559-567, 2013.

KURTZ, C; PAULETTI, V.; FAYAD, J. A.; VIEIRA NETO, J. Crescimento e absorção de nutrientes pelo cultivar de cebola Bola Precoce. Horticultura Brasileira, v.34, p.279288, 2016.

LARENTZAKI, E.; PLATE, J.; NAULT, B. A.; SHELTON, A. M. Impact of straw mulch on populations of onion thrips (Thysanoptera: Thripidae) in onion. Journal of Economic Entomology, v.101, n.4, p.317-1324, 2008.

LEE, J. Effect of application methods of organic fertilizer on growth, soil chemical properties and microbial densities in organic bulb onion production. Scientia Horticulturae, v.124, p.299-305, 2010.

MADEIRA, N. R.; OLIVEIRA, V. R.; HAMERSCHMIDT, I. Cultivo de cebola em sistema de plantio direto. Curitiba: Instituto EMATER, 2013.

MARCUZZO, L. L.; MENEZES JÚNIOR, F. O. G.; GONCALVES, P. A. S. Severidade do míldio da cebola em diferentes sistemas de produção. Summa Phytopathologica, v.42, n.4, p.366-368, 2016.

MARCUZZO, L. L.; ARAÚJO, E. R. Manejo de doenças. In: MENEZES JÚNIOR, F. O. G.; MARCUZZO, L. L. (org.) Manual de boas práticas agrícolas: guia para a sustentabilidade das lavouras de cebola do estado de Santa Catarina. Florianópolis: Epagri, 2016. Cap. 9, p.91-111.

MARCUZZO, L. L.; CARVALHO, J.; NASCIMENTO, A. Aspectos epidemiológicos do míldio da cebola na região do alto vale do Itajaí em Santa Catarina. Summa

Phytopathologica, Botucatu, v.43, n.3, p.218-222, 2017.

MENEZES JÚNIOR, F. O. G. VIEIRA NETO, J. Produção da cebola em função da densidade de plantas. Horticultura Brasileira, v.30, p.733-739, 2012.

MENEZES JÚNIOR, F. O. G.; GONÇALVES, P. A. S.; VIEIRA NETO, J. Revista de Ciências Agroveterinárias, v.12, p.264-270, 2013. 
MENEZES JÚNIOR, F. O. G.; GONCALVES, P. A. S.; VIEIRA NETO, J. Produtividade da cebola em cultivo mínimo no sistema convencional e orgânico com biofertilizantes. Horticultura Brasileira, v.32, p.475-481, 2014.

MENEZES JÚNIOR, F. O. G. As boas práticas agrícolas e a produção integrada: Diferenças e indicações gerais de procedimentos das BPAs. In: MENEZES JÚNIOR, F. O. G.; MARCUZZO, L. L. (Eds.). Manual de práticas agrícolas: guia para a sustentabilidade das lavouras de cebola do estado de Santa Catarina. 1. ed. Florianópolis: Departamento Estadual de Marketing e Comunicação (DEMC) / Epagri, p.17-24. 2016.

MENEZES JÚNIOR, F. O. G.; GONÇALVES, P. A. S.; MARCUZZO, L. L. Avaliação de produtividade de cebola em sistemas de produção convencional, racionais e orgânicos. In: CONGRESSO BRASILEIRO DE OLERICULTURA, 53., 2014, Palmas. Anais... Palmas: TO da $\mathrm{ABH}, 2014$.

MENEZES JÚNIOR, F. O. G.; GONCALVES, P. A. S.; MARCUZZO, L. L. Avaliação de sistemas de produção convencional, racionais e orgânicos na cultura da cebola em plantio direto no Alto Vale do Itajaí - SC. Revista Thema, v.15, n.3, p.1123-1136, 2018.

SANTOS, S. S.; ESPÍNDOLA, J. A. A.; GUERRA, J. G. M.; LEAL, M. A. A.; RIBEIRO, R. L. D. Produção de cebola orgânica em função do uso de cobertura morta e torta de mamona. Horticultura Brasileira, v.30, p.549-552, 2012.

SCOPEL, E.; DOUZET, J. M.; SILVA, F. A. M.; CARDOSO, A.; MOREIRA, J. A. A.; FINDELING, A.; BERNOUX, M. Impactos do sistema de plantio direto com cobertura vegetal (SPDCV) sobre a dinâmica de água, do nitrogênio mineral e do carbono do solo do cerrado brasileiro. Cadernos de Ciência e Tecnologia, v.22, p.169-183, 2005.

SCHWARTZ, H. F.; GENT, D. H.; FICHTNER, S. M.; HAMMON, R.; CRANSHAW, W. S.; MAHAFFEY, L.; CAMPER, M.; OTTO, K.; MCMILLAN, M. Straw mulch and reduced-risk pesticide impacts on thrips and Iris yellow spot virus on western-grown onions. Southwestern Entomologist, v.34, n.1, p.13-29, 2009.

VIDIGAL, S. M.; SEDIYAMA, M. A. N.; PEDROSA, M. W.; SANTOS, M. R. Produtividade de cebola em cultivo orgânico utilizando composto à base de dejetos de suínos.

Horticultura Brasileira, v.28, p.168-173, 2010.

WAIGANJO, M. M.; GITONGA, L. M.; MUEKE, J. M. Effects of weather on thrips population dynamics and its implications on the thrips pest management. African Journal of Horticultural Science, n.1, p.82-89, 2008.

WORDELL FILHO, J. A.; BOFF, P. Doenças de origem parasitária. In: WORDELL FILHO, J. A.; ROWE, E.; GONÇALVES, P. A. S.; DEBARBA, J. F.; BOFF, P.; THOMAZELLI, L. F. Manejo fitossanitário na cultura da cebola. Florianópolis: Epagri, 2006. p.19-162.

WORDELL FILHO, J. A.; STADNIK, M. J. Efeito de produtos alternativos no controle do míldio e na produtividade da cebola no Alto Vale do Itajaí. Agropecuária

Catarinense, Florianópolis, v.19, n.1, p.40-45, 2006. 